\title{
Effect of Polyethylene Glycol on the Mechanical Alloying Behavior of Cu-W Electrical Contact Material
}

\author{
S. BIYIK* \\ Karadeniz Technical University, Abdullah Kanca Vocational School, \\ Department of Machinery and Metal Technologies, 61530 Trabzon, Turkey
}

\begin{abstract}
In this study, the effect of polyethylene glycol on the particle size and morphology of Cu25W composite powder was investigated. For this purpose, commercial elemental copper and tungsten powders were milled in a planetary-type ball mill. Milling conditions, namely ball-to-powder weight ratio and milling speed, were selected to be 10:1 and $300 \mathrm{rpm}$, respectively. In order to avoid agglomeration and to decrease the tendency of cold welding among powder particles, polyethylene glycol at the amount of $2 \mathrm{wt} \%$ was used as a process control agent. Morphological evolution of milled powders was investigated using scanning electron microscopy. In addition, the variation of particle size as a function of milling duration was examined using laser diffraction analysis. It was found that powder particle size gradually decreased with increasing milling duration. However, compared to the powder mixture without the process control agent, the powder mixture containing polyethylene glycol tends to lower the milling duration to achieve the same amount of particle size reduction. As a result of this effort, the usage of polyethylene glycol as a process control agent was found to be effective to obtain a composite powder with smaller particle sizes, especially in the earlier stages of milling process.
\end{abstract}

DOI: 10.12693/APhysPolA.134.208

PACS/topics: ball milling, copper-based electrical contact materials, composites, powder metallurgy, tungsten

\section{Introduction}

Electrical contacts have a major influence on the electrical performance and reliability of electromagnetic switches, such as relays and contactors [1]. The contact surfaces can deteriorate with increasing number of switching operations due to the arc-originated overheating and substantial material losses $[2,3]$. These situations may eventually result in failure of electrical contacts, and therefore they must be minimized by compositional arrangements and/or production methods [4].

For these reasons, it is necessary to produce electrical contact materials having some performance requirements, such as high electrical conductivity, to minimize the heat generated during passage of current; high thermal conductivity to dissipate both the resistive and arc heat; high resistance to chemical reactions in all application environments, so as to avoid formation of insulating oxides, sulfides, and other compounds; and immunity to arcing damage on the making and breaking of electrical contact [5]. However, there is no universal contact material which suits the entire range of high power applications. Therefore, depending on the type of application, contact materials should be optimized to provide reliability, long contact life and low cost [6]. Much work has been done towards producing and evaluating the electrical performances of contact materials [6-18].

Commercially pure copper $(\mathrm{Cu})$ has an electrical conductivity exceeded only by silver, and this, together with its ready availability in a wide variety

\footnotetext{
*e-mail: serkanbiyik@ktu.edu.tr
}

of forms, and its low cost and plentiful supply compared with precious metals, makes it an obvious choice as a contact material [19].

However, $\mathrm{Cu}$ has also some drawbacks such as poor resistance to corrosion and tendency to form heavy oxide films of relatively high resistance [20]. Therefore, $\mathrm{Cu}$ is frequently combined with certain metals, metal oxides and non-metallic materials to produce a material with optimum properties [21-25]. For example, different types of $\mathrm{Cu}$-based composite electrical contact materials have been developed to meet requirements for various applications, such as arcing contacts in oil switches, current carrying contacts, vacuum interrupter, oil-circuit breakers, arcing tips, contactors, vacuum switches, automotive starters, instruments, fuel pumps, welding machines, industrial truck motors, automotive heaters, antenna motors and generators, etc. [5]. These types of compositions ordinarily cannot be achieved by alloying. They are mainly obtained by powder metallurgy (PM) method.

PM method is frequently combined with ball milling technique which includes repeated cold welding, fracture and rewelding of powder particles in a high-energy ball mill, and therefore it enables to obtain fine and homogeneous dispersion of brittle phase in the ductile matrix. However, this technique has several parameters that need to be optimized (such as ball-to-powder weight ratio (BPR), milling speed, milling duration, etc.) to enhance ball milling process efficiency [21].

Besides, some surface additives called process control agents (PCA) are required to establish a balance between cold welding and fracture events. It should also be emphasized that the non-use of the PCA leads to excessive cold welding which inhibits further size reduction, especially in compositions containing a substantial fraction of 
ductile component [26]. Hence, the effect of PCA with increasing milling duration should be carefully studied. For this aim, the present study investigated the effect of polyethylene glycol (PEG) on synthesis of $\mathrm{Cu} 25 \mathrm{~W}$ composite powder.

\section{Experimental procedures}

In the present study, commercial elemental $\mathrm{Cu}(44 \mu \mathrm{m}$, $99 \%$ purity) and $\mathrm{W}$ (average particle size (APS) of $12 \mu \mathrm{m}$, 99.9\% purity) powders were used as the matrix and reinforcement materials, respectively. Morphology of the starting or as-received powders is shown in Fig. 1.
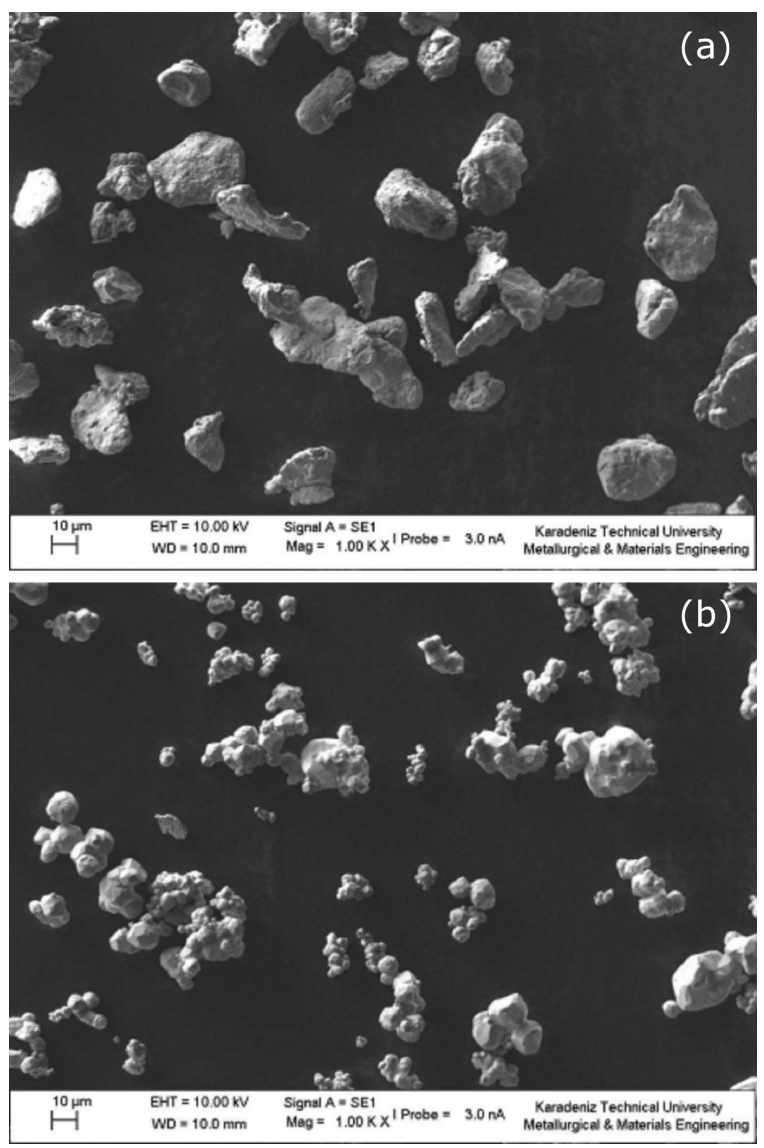

Fig. 1. Morphology of as-received (a) $\mathrm{Cu}$ and (b) W powders.

$\mathrm{W}$ powder was added to $\mathrm{Cu}$ powder in the amount of $25 \mathrm{wt} \%$. In order to avoid agglomeration and to decrease the tendency of cold welding among powder particles, PEG at the amount of $2 \mathrm{wt} \%$ was used as a PCA. A twostationary planetary-type ball mill (Retsch PM 200) was used to conduct milling experiments with a milling speed of $300 \mathrm{rpm}$ and a BPR of 10:1. The milling conditions during the synthesis of $\mathrm{Cu} 25 \mathrm{~W}$ composite powder are given in Table I.

Morphological evolution of the powder mixture with increasing milling duration was investigated using scanning electron microscopy (SEM; Zeiss Evo LS 10). After
Ball milling conditions used to syn-

TABLE I thesize Cu25W composite powder.

\begin{tabular}{l|c}
\hline \hline $\begin{array}{l}\text { type of mill } \\
\text { milling container } \\
\text { grinding medium } \\
\text { type of PCA } \\
\text { milling energy/speed }[\mathrm{rpm}] \\
\text { milling time }[\mathrm{h}] \\
\text { BPR }\end{array}$ & $\begin{array}{c}\text { planetary ball mill } \\
\text { tungsten carbide }(\mathrm{WC}) \\
\text { WC balls }(\Phi=10 \mathrm{~mm}) \\
\text { polyethylene glycol }(\mathrm{PEG})\end{array}$ \\
& $0.5,2,4,100$ \\
& $10: 1$
\end{tabular}

certain number of hours of milling operation (Table I), the powder samples were withdrawn from the vial for particle size measurements. The variation of particle size as a function of milling duration was examined using laser diffractometry (Mastersizer 2000, Malvern Instruments).

\section{Results and discussion}

It can be seen from Fig. 1a that $\mathrm{Cu}$ powder grains have an irregular shape, whereas $\mathrm{W}$ powder grains have an angular shape (Fig. 1b) from a morphological point of view. In addition, Fig. 1 also proves that starting powder particle size of the reinforcement material (W) is much smaller than that of the matrix material $(\mathrm{Cu})$.

The APS values of the $\mathrm{Cu} 25 \mathrm{~W}$ powder mixture with respect to PEG content and milling duration are listed in Table II. Figure 2 shows particle size variation of $\mathrm{Cu} 25 \mathrm{~W}$ powder mixture as a function of PEG content and milling duration. The curves in Fig. 2 were basically plotted by using APS values from Table II. It was found that particle size generally decreased with increasing milling duration. However, in the very early stages of milling process, especially at certain values corresponding to $0.5-4 \mathrm{~h}$, fluctuation in particle size occurs in the powder mixture milled without the PCA (Fig. 2).

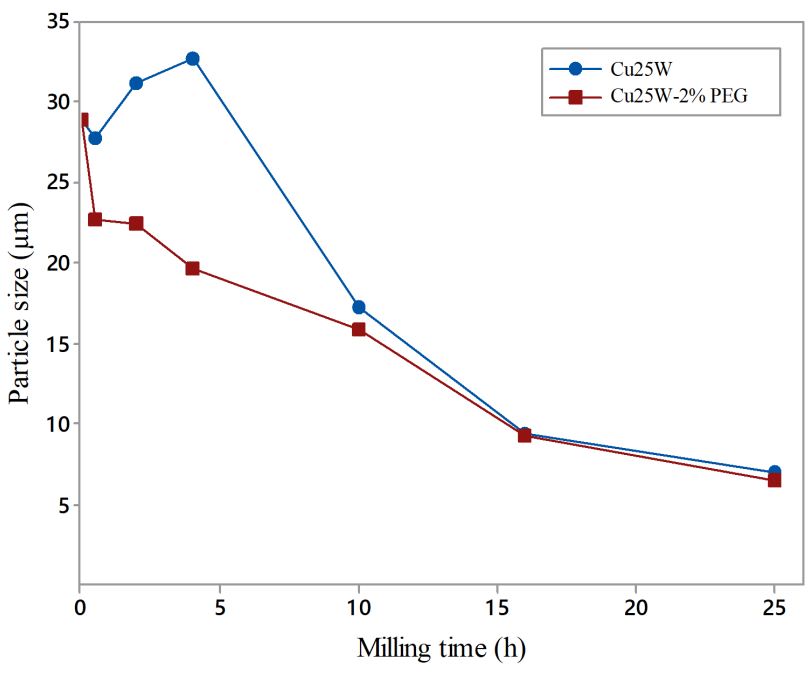

Fig. 2. Particle size variation of $\mathrm{Cu} 25 \mathrm{~W}$ powder mixture as a function of PEG content and milling duration. 

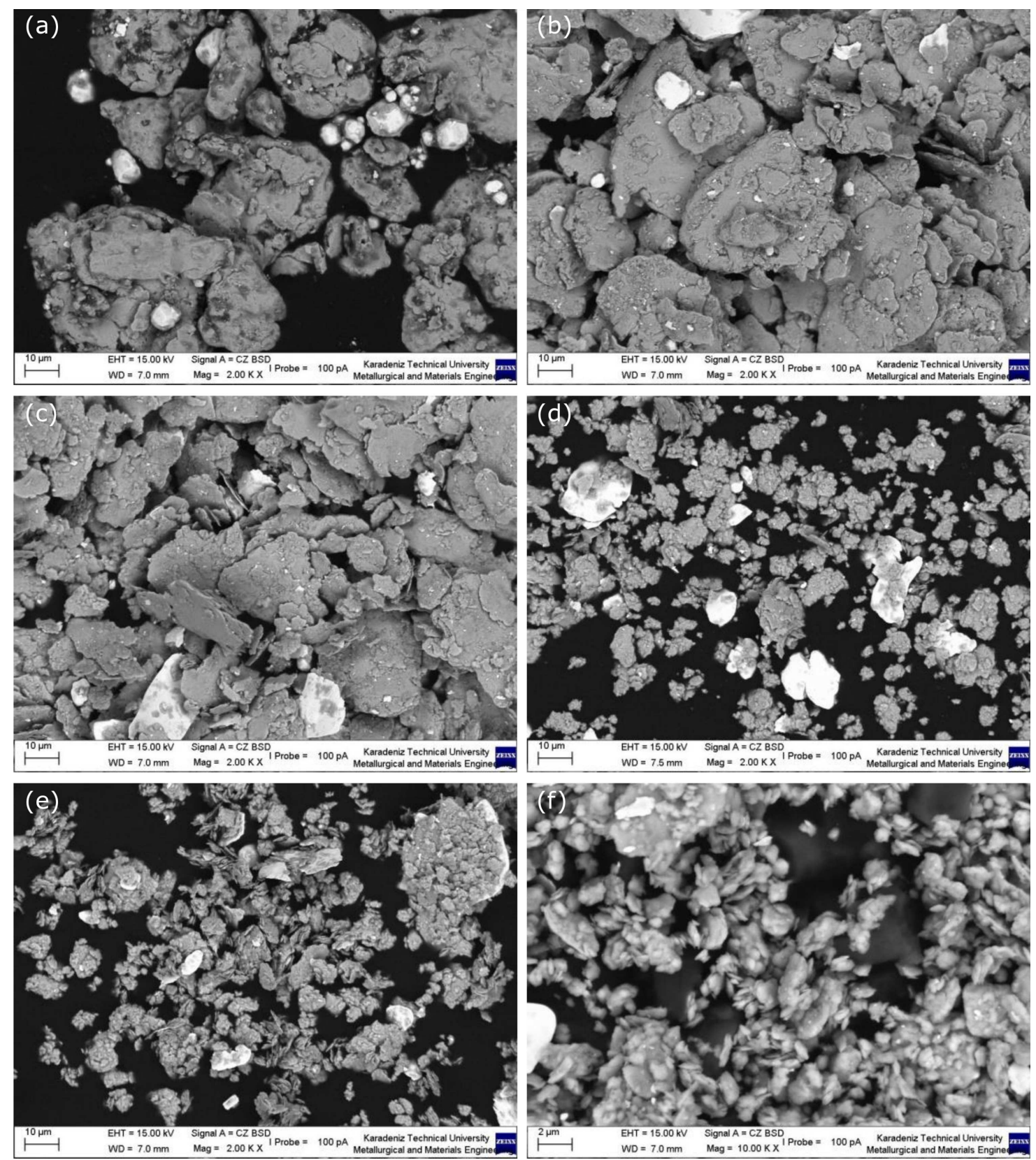

Fig. 3. Morphological evolution of Cu25W powder mixture containing 2 wt\% PEG after milling for various durations; (a) 0.5 , (b) 2 , (c) 4, (d) 10 , (e) 16 and (f) $25 \mathrm{~h}$.

Average particle size values with respect to PEG content and milling duration.

TABLE II

\begin{tabular}{c|c|c|c|c|c|c|c}
\hline \hline Composition & \multicolumn{7}{|c}{ Milling duration $[\mathrm{h}]$ and $d_{50}[\mu \mathrm{m}]$} \\
\cline { 2 - 7 } and amount of PEG & 0 & 0.5 & 2 & 4 & 10 & 16 & 25 \\
\hline Cu25W, 0\% PEG & 28.897 & 27.771 & 31.256 & 32.76 & 17.225 & 9.366 & 6.964 \\
Cu25W, 2\% PEG & 28.897 & 22.666 & 22.442 & 19.654 & 15.867 & 9.3 & 6.5
\end{tabular}

The shape of powder particles with increasing milling duration.

TABLE III

\begin{tabular}{c|c|c|c|c|c|c|c}
\hline \hline Composition & \multicolumn{7}{|c}{ Milling duration [h] and powder morphology } \\
\cline { 2 - 7 } and amount of PEG & 0 & 0.5 & 2 & 4 & 10 & 16 & 25 \\
\hline Cu25W, 2\% PEG & irregular & $\begin{array}{c}\text { irregular } \\
+ \text { flaky }\end{array}$ & flaky & flaky & $\begin{array}{c}\text { flaky } \\
+ \text { semi-equiaxed }\end{array}$ & semi-equiaxed & equiaxed
\end{tabular}


Milling duration of $16 \mathrm{~h}$ may be referred to as the threshold point in terms of particle size reduction for each powder mixture. It is clear from Fig. 2 that powder mixtures exhibited almost the same trend for the milling durations between 10 to $25 \mathrm{~h}$. The minimum line particle size $(6.5 \mu \mathrm{m})$ is obtained in the powders having a PEG of $2 \mathrm{wt} \%$ after milling for $25 \mathrm{~h}$.

Figure 3 shows the morphological evolution of $\mathrm{Cu} 25 \mathrm{~W}$ powder mixture containing 2 wt\% PEG after milling for various milling durations, namely $0.5,2,4,10,16$ and $25 \mathrm{~h}$.

In the early stages of ball milling process each of the soft metal powder particles is flattened by ball-powderball collisions (Fig. 3a). As can be seen from Fig. 3b, coarsening of $\mathrm{Cu}$ particles is observed with increasing milling operations. It may be emphasized that the powder particles have a range of sizes and that most of the particles have flaky and irregular morphology up to milling duration of $4 \mathrm{~h}$ (Fig. $3 \mathrm{a}-\mathrm{c})$. The large fluctuation of powder particle size at the very beginning of the milling process is attributed to the existence of these flaky powder particles. Hence, the balance between cold welding and fracture is not provided up to milling duration of $4 \mathrm{~h}$.

On the other hand, fracture events start to dominate over cold welding after the milling duration of $4 \mathrm{~h}$. Cold welded $\mathrm{Cu}$ particles were fragmented into smaller pieces. However, formation of coarse $\mathrm{W}$ reinforcement powder particles is also observed after the milling duration of $10 \mathrm{~h}$ (Fig. 3d). The changes in powder morphology with respect to increasing milling duration are listed in Table III. The powder morphology is transformed from flaky to flaky plus semi-equiaxed after $10 \mathrm{~h}$.

The later stages of ball milling process are characterized by a narrow particle size distribution and the composition becoming almost uniform after the milling duration of $16 \mathrm{~h}$ (Fig. 3e). Powder particle size is reduced from 15.867 to 9.3 microns in this period and the powder morphology is transformed into semi-equiaxed. Microstructural refinement continues to take place up to milling duration of $25 \mathrm{~h}$, and the refractory metal dispersion (W) becomes more uniform (Fig. 3f). As a result of this effort, equiaxed morphology is achieved with an APS of 6.5 microns.

It is clear from Fig. 2 that the rate of particle size reduction slows down after the milling duration of $16 \mathrm{~h}$. The most efficient size reduction is observed at milling durations ranging between 4 to $16 \mathrm{~h}$ for both compositions.

\section{Conclusions}

Powder particle size gradually decreases with increasing milling duration except for the very beginning of milling operation. Compared to the powder mixture milled without PCA, the powder mixture milled with $2 \mathrm{wt} \%$ of PEG exhibited shorter milling durations to achieve the same amount of particle size reduction. As a result of this effort, the usage of PEG as a PCA was found to be effective to obtain a composite powder with smaller particle sizes, especially up to $10 \mathrm{~h}$. However, the rate of particle size reduction decreases after $16 \mathrm{~h}$ in milled powders containing PEG, and therefore each powder mixture exhibits almost same regime in milling durations between 16 to $25 \mathrm{~h}$. Equiaxed powder morphology with an APS of 6.5 microns is achieved as a result of narrow size distribution. The most efficient size reduction is observed in the range that corresponds to milling durations between 4 to $16 \mathrm{~h}$ for both compositions.

\section{References}

[1] P.G. Slade, Electrical Contacts: Principles and Applications, CRC, Boca Raton, FL 2014.

[2] S. Biyik, M. Aydin, Acta Phys. Pol. A 129, 656 (2016).

[3] V. Gurevich, Electric Relays: Principles and Applications, CRC, Boca Raton, FL 2005.

[4] M. Braunovic, N.K. Myshkin, V.V. Konchits, Electrical Contacts: Fundamentals, Applications and Technology, CRC, Boca Raton, FL 2006.

[5] ASM Handbook volume 2: Properties and Selection: Nonferrous Alloys and Special-Purpose Materials, ASM International, Ohio 1990.

[6] S. Biyik, F. Arslan, M. Aydin, J. Electron. Mater. 44 457 (2015).

[7] Y.P. Wang, H.Y. Li, Metall. Mater. Trans. A 48, 609 (2017).

[8] H. Li, X. Wang, Y. Liu, X. Guo, Vacuum 135, 55 (2017).

[9] Z.J. Wei, L.J. Zhang, Q.H. Shen, L.S. Chen, X.P. Fan, H. Yang, Rare Metal Mat. Eng. 45, 513 (2016).

[10] L. Dong, W. Chen, N. Deng, J. Song, J. Wang, J. Alloy. Compd. 696, 923 (2017).

[11] Z.J. Lin, S.H. Liu, J.G. Li, J.L. Chen, M. Xie, X.D. Li, M. Zhang, Q. Zhu, D. Huo, X.D. Sun, Mater. Design 108, 640 (2016).

[12] H. Li, X. Wang, X. Guo, X. Yang, S. Liang, Mater. Design 114, 139 (2017).

[13] G.J. Li, H.J. Cui, J. Chen, X.Q. Fang, W.J. Feng, J.X. Liu, J. Alloy. Compd. 696, 1228 (2017).

[14] X.H. Zheng, F.E. Yang, L.J. Zhang, J. Zhang, T. Shen, L.S. Chen, Rare Metal Mat. Eng. 45, 206 (2016).

[15] Z.J. Wei, L.J. Zhang, T. Shen, Z.Y. Qiao, H. Yang, X.P. Fan, L. Chen, J. Mater. Eng. Perform. 25, 3662 (2016).

[16] A. Moghanian, F. Sharifianjazi, P. Abachi, E. Sadeghi, H. Jafarikhorami, A. Sedghi, J. Alloy. Compd. 698, 518 (2017).

[17] N. Ray, B. Kempf, T. Mutzel, F. Heringhaus, L. Froyen, K. Vanmeensel, J. Vleugels, J. Alloy. Compd. 670, 188 (2016).

[18] S. Biyik, M. Aydin, Acta Phys. Pol. A 131, 339 (2017).

[19] H. W. Turner, C. Turner, Copper in Electrical Contacts, CDA, Surrey 1997. 
[20] ASM Handbook volume 7: Powder Metal Technologies and Applications, ASM International, Ohio 1998.

[21] S. Biyik, M. Aydin, Acta Phys. Pol. A 127, 1255 (2015).

[22] W. Chen, L. Dong, Z. Zhang, H. Gao, J. Mater. Sci.: Mater. El. 27, 5584 (2016).
[23] P.G. Slade, IEEE Trans. Compon. Pack. Manuf. Technol. A 17, 96 (1994).

[24] S. Biyik, Acta Phys. Pol. A 132, 886 (2017).

[25] S. Biyik, M. Aydin, Acta Phys. Pol. A 132, 909 (2017).

[26] C. Suryanarayana, Mechanical Alloying and Milling CRC, Boca Raton, FL 2004. 